\title{
Ship System Maintenance Strategy Selection Based on DELPHI-AHP-TOPSIS Methodology
}

\author{
Ikuobase Emovon \\ Department of Marine Engineering, Federal University of Petroleum Resources, Effurun, Nigeria \\ Email: i.emovon@newcastle.ac.uk, ikuoy2k@yahoo.com
}

Received 16 January 2016; accepted 16 May 2016; published 19 May 2016

Copyright (C) 2016 by author and Scientific Research Publishing Inc.

This work is licensed under the Creative Commons Attribution International License (CC BY). http://creativecommons.org/licenses/by/4.0/

c) (7) Open Access

\begin{abstract}
Maintenance decision problems generally involve multiple criteria which apparently are best addressed using Multi-Criteria Decision Making (MCDM) tools. This paper describes the use of a hybrid MCDM technique in prioritizing maintenance strategy for ship systems. The Hybrid MCDM technique combines Delphi method, AHP and TOPSIS methods. While the Delphi method and AHP are applied in screening of decision criteria and decision criteria weights determination respectively, the TOPSIS method is used in the ranking of alternative maintenance strategies. Five alternative maintenance strategies which include corrected maintenance, scheduled overhaul, scheduled replacement, continuous on-condition task and scheduled on-condition task are considered and the optimum maintenance strategy is selected based on twelve critical maintenance decision criteria. To demonstrate the suitability of the approach a case study of sea water pump of the central cooling system of a marine diesel engine is used.
\end{abstract}

\section{Keywords}

TOPSIS Method, Maintenance Strategy, Ship System, Delphi Method, Decision Criteria

\section{Introduction}

Shipping industry is generally faced with the pressure of reducing maintenance cost which does account for $20 \%$ to $40 \%$ of total operational cost of ship. However, care must be taken in reducing maintenance cost in order not to negatively impact on ship safety and reliability. To achieve this objective, an efficient maintenance system must be put in place. British Standard defines maintenance as [1] "the combination of all technical and administrative actions, intended to retain an item in, or restore it to, a state in which it can perform a required action. In recent years, the increasing complexity of ship systems has led to a consistent complexity in maintenance activities [2], together with a rise in the required human resource and costs [3]. There are majorly three elements 
that make up a maintenance system and these are risk assessment, maintenance strategy selection and maintenance interval determination. These elements must be properly carried out to achieve optimum ship system safety and reliability. It is then obvious that one of the main challenges of maintenance management is the selection of the suitable maintenance strategy for each equipment item in the ship system because not all maintenance strategies are applicable and cost effective for different components. There basically two main maintenance strategies: corrective and preventive [4]. "The corrective maintenance is undertaken when an equipment has failed while the preventive maintenance is performed when the equipment is still in operating condition so as to reduce probability of failure" [5]. The preventive maintenance is either performed on the equipment based on the equipment condition or industrial life of the equipment. Rausand and Vatn [6] classify maintenance from the Reliability Centered Maintenance (RCM) point of view as corrective maintenance, scheduled overhaul, scheduled replacement, scheduled on-condition task and continuously condition task. These five divisions of maintenance are considered in this paper for ship system maintenance and from among which optimum strategy are selected for different equipment items.

Reliability Centered Maintenance logic tree has been applied in the selection of optimum maintenance strategy for equipment items of the ship system [7] [8]. However, the use of RCM is a very time consuming exercise [4] and this may be attributed to the delay in arriving at consensus solution among RCM team for each of the equipment item of the ship system. Furthermore the technique does not allow for ranking of maintenance alternatives such that the optimum maintenance strategy can easily be selected.

In addressing the problem of maintenance strategy selection for ship system, a Multi-Criteria Decision Making (MCDM) tool based on Analytical Hierarchy Process (AHP) has been proposed. Goossens and Basten [9] use AHP in the selection of appropriate maintenance strategies for naval ship systems. Three level decision criteria are applied in selecting the optimal maintenance strategy from among three maintenance strategies: corrective, time/use-based maintenance and condition based maintenance for the ship system. The first level consists of two decision criteria; the second level consists of eight and the third level consisted of 29. Although the analysed results produce condition based maintenance as optimum maintenance strategy for ship systems is line with current practice for critical equipment. However, the structuring of the problem makes the evaluation process cumbersome as it requires formation and analysis of numerous pairwise judgements from experts.

Resobowo, Buda and Dinariyana [10] also applied AHP in prioritizing the decision criteria such as cost, availability, reliability, safety, human resource, operations, types of ship and ship characteristics that affect military ship maintenance management. The approach did not completely address the problem of maintenance strategy selection as the authors were mainly interested in identifying the most critical decision criteria for determining optimum maintenance strategy for ship systems.

This paper considered a hybrid MCDM approach which integrates Delphi method, AHP and TOPSIS for maintenance strategy selection for ship systems. The purpose of combining the Delphi method and TOPSIS with the AHP technique was to eliminate the weaknesses of the AHP. Although the AHP method has both the capability of determining decision criteria weights and ranking of maintenance strategy alternatives but the major challenge being the difficulty in the formation and evaluation of numerous pairwise judgement especially when more than fifteen criteria are applied in the decision making process. The Delphi technique was introduced to screen decision criteria such that the most important decision criteria are used in the decision process and TOPSIS is applied in the ranking of maintenance strategy alternatives respectively. The AHP technique was only applied in the determination of decision criteria and as such the number of pairwise judgement that need to be form and evaluated are few and invariably less computationally intensive decision making process.

The paper is organised as follows: Section 2 presents the proposed methodology; Section 3 describes the various maintenance strategies identified for ship systems application; in Section 4 the case of central water cooling system is presented to demonstrate the proposed methodology. Section 5 dealt with data gathering and analysis; finally the conclusion is presented in Section 6.

\section{Methodology}

\subsection{Delphi Method}

The Delphi method which is repeatedly used in collecting and analysing opinions of experts until a consensus is reached in resolving a decision problem [11]. Some of the merits of the Delphi technique are 1) participant experts can freely express their opinions since information is anonymously sourced creating no room for domi- 
neering experts to dictate the outcome which is usually the case of the conventional brainstorming technique [12] and 2) the process is cheap since through email, surface mail and sometimes face to face contact with individual participant experts, the researcher or investigator can obtain a consensus opinion from participating experts on an issue as compared to the traditional brainstorming technique where experts will need to convene in one place to reach a consensus.

The first step involves preparing a questionnaire and sending it to group of experts through means such as surface post and email. The responses are then obtained and processed. This is referred to the first round of the Delphi process. Based on the result of the first round a modified questionnaire is sent to the group of experts and again responses are obtained and analysed. This is the second round of the Delphi process. In most cases consensus are reached in the second round.

\subsection{TOPSIS Method}

The TOPSIS method is a popular MCDM technique and was first proposed in 1981 by Yoon and Hwang [13]. The technique had been applied in the ranking of alternatives through distance measure. The optimum alternative is generally the one closest to the positive ideal solution. The methodological steps for TOPSIS analysis are as follows [14] [15]:

(1) Determination of the decision matrix: The decision matrix, $X$, can be represented as follows

$$
\begin{aligned}
& \begin{array}{lllll}
B_{1} & B_{2} & B_{3} \cdots & B_{n}
\end{array} \\
& X=\begin{array}{c}
A_{1} \\
A_{2} \\
A_{3} \\
\vdots \\
A_{m}
\end{array}\left[\begin{array}{ccccc}
x_{11} & x_{12} & x_{13} & \ldots & x_{1 n} \\
x_{21} & x_{22} & x_{23} & \ldots & x_{2 n} \\
x_{31} & x_{32} & x_{33} & \ldots & x_{3 n} \\
\vdots & \vdots & \vdots & \ddots & \vdots \\
x_{m 1} & x_{m 2} & x_{m 3} & \ldots & x_{m n}
\end{array}\right]
\end{aligned}
$$

where $A_{i}$ represent alternative maintenance $i, \quad i=1, \cdots, m ; B_{j}$ denotes decision criteria $j, j=1, \cdots, n$ on the basis of which alternatives are judged. $x_{i j}$ represent $j$ th criteria with respect to $i t h$ alternative maintenance.

(2) Determination of normalised decision matrix

$$
f_{i j}=\frac{x_{i j}}{\sqrt{\sum_{i=1}^{m} x_{i j}^{2}}}, i=1, \cdots, m ; j=1, \cdots, n
$$

(3) Determination of the weighted normalised decision matrix

The weighted normalised decision matrix can be calculated by multiplying the normalised decision matrix by the weight of decision criteria and is expressed as:

$$
v_{i j}=w_{j} f_{i j}, i=1, \cdots, m ; j=1, \cdots, n
$$

where $w_{j}$ is the weight of the $j$ th criterion. There are several technique available in the literature for the evaluation of criteria weights. The approach chosen in this paper is the AHP method because of its ability to utilised both qualitative and quantitative information in determining weights of decision criteria.

(4) Determination of the positive-ideal and negative-ideal solutions

The positive ideal solution and the negative ideal solution are evaluated respectively as follows:

$$
\begin{aligned}
& Z^{+}=\left\{v_{1}^{+}, v_{2}^{+}, \cdots, v_{j}^{+}\right\}=\left\{\left(\max _{i} v_{i j} \mid j \in I\right),\left(\min _{i} v_{i j} \mid j \in I^{\prime}\right)\right\} \\
& Z^{-}=\left\{v_{1}^{-}, v_{2}^{-}, \cdots, v_{j}^{-}\right\}=\left\{\left(\min _{i} v_{i j} \mid j \in I\right),\left(\max _{i} v_{i j} \mid j \in I^{\prime}\right)\right\}
\end{aligned}
$$

where $I$ is associated with the benefit criteria and $I^{\prime}$ is associated with cost criteria.

(5) Calculation of the separation measure

The separation of each alternative from the positive-ideal solution and from the negative-ideal solution, are evaluated, respectively as: 


$$
\begin{gathered}
S_{i}^{+}=\left\{\sum_{j=1}^{n}\left(v_{i j}-v_{j}^{+}\right)^{2}\right\}^{\frac{1}{2}} \quad i=1,2, \cdots, m ; j=1,2, \cdots, n \\
S_{i}^{-}=\left\{\sum_{j=1}^{n}\left(v_{i j}-v_{j}^{-}\right)^{2}\right\}^{\frac{1}{2}} \quad i=1,2, \cdots, m ; j=1,2, \cdots, n
\end{gathered}
$$

(6) Calculation of the relative closeness to the positive ideal solution.

The relative closeness $P_{i}$ of the alternatives to the positive ideal solution is evaluated as follows:

$$
P_{i}=\frac{S_{i}^{-}}{S_{i}^{+}+S_{i}^{-}}, \quad i=1, \cdots, m
$$

The alternative with the maximum $P_{i}$ value is the optimum solution.

However in many practical situations multiple experts or a group of experts are involved in the decision making process thereby bringing a great deal of complexity into the use of MCDM methods [16]. Different aggregation methods are available for combining experts' preferences in group decision making. Either rank or score aggregation can be used. In this paper the score aggregation technique was chosen because rank aggregation may lead to rank reversal. In aggregating the scores of individual experts a simple arithmetic mean can be applied. The average of the individual experts TOPSIS scores for each maintenance alternative are referred to here as overall scores. On the basis of the overall score, maintenance strategy alternatives are ranked and the highest ranked chosen as the optimum solution.

\section{Alternative Maintenance Strategies}

Five alternative maintenance strategies mostly used within the framework of RCM are evaluated in this paper based on 12 different decision criteria. The five maintenance strategies are described briefly in Table 1.

\section{Case Study of Sea Water Pump of Central Cooling System of Marine Diesel Engine}

The prioritisation of risk of failure modes of the marine diesel engine had been carried out in previous research [19]. From the study, one of the equipment items/components with the greatest failure consequence on the marine diesel engine was found to be the sea water pump of the sea water cooling system which form part of the central cooling system. On this basis, the sea water (SW) pump was chosen to demonstrate the applicability of the proposed methodology for the selection of a maintenance strategy. The line diagram in Figure 1 is a typical central cooling system which is normally used for a small size bulk carrier and consisting of three pumps which takes water from the pipe linked to both the high sea chest and low sea chest. The sea water is then used to cool the fresh water in the central coolers which in turn cool the marine diesel engine. It is then obvious that the sea water pump is central to the operation of the central cooling system of the marine diesel engine.

\section{Data gathering and Analysis}

\subsection{Delphi Method Analysis}

Ten experts which comprises of 5 five academia and 5 from the shipping industry were selected. This was followed with the development of questionnaires based on 22 decision criteria obtained from literature. The questionnaires were then sent to the ten experts. Responses were then obtained and processed. Based on the result of the first round a modified questionnaire was sent to the ten experts and again responses were obtained and analysed. From the two round Delphi analysis of the 22 decision criteria, the number was reduced from 22 to 12. The twelve decision criteria are discussed as follows:

Spare parts inventories $(C 1)$. The amount of spare parts that should be available for each type of maintenance strategy.

Maintenance cost (C2). Cost of equipment, materials and labour for each maintenance strategy.

Crew training cost (C3). The cost that may be incur in training staff in order for them to have the required skills to use tools and techniques for performing maintenance task. 
Table 1. Types of maintenance strategy.

\begin{tabular}{|c|c|}
\hline Maintenance strategies & Description \\
\hline Corrective maintenance (CM) & $\begin{array}{l}\text { This is maintenance management in which plant system or equipment item are allow to breakdown } \\
\text { before being fixed. It is generally applied to low cost and low risk equipment. }\end{array}$ \\
\hline Scheduled overhaul $(\mathrm{SOH})$ & $\begin{array}{l}\text { A maintenance approach in which equipment overhaul or repair is carried out at a specified interval } \\
\text { basis. This policy is suitable for equipment or machinery with identifiable age when failure rate function } \\
\text { rapidly increases and large elements of the equipment or machine must survive to that age and also } \\
\text { where reworking can restore the machine to an acceptable operational condition [17]. }\end{array}$ \\
\hline Scheduled replacement (SRP) & $\begin{array}{l}\text { This refers to maintenance techniques in which equipment or a unit of it is replaced on a scheduled basis. } \\
\text { This is usually ideal when equipment or machines are exposed to critical failure; large units of the } \\
\text { equipment or machines must survive to the least the replacement time and the failure type must be of } \\
\text { major economic consequences [17]. }\end{array}$ \\
\hline Continuous on-condition task & $\begin{array}{l}\text { The continuous on-condition task is also referred to as online condition based maintenance (ONCBM) } \\
\text { in this paper and is the approach in which the condition of an equipment item is monitored } \\
\text { uninterruptedly using diagnostics devices. The major disadvantage of this type of approach is that it is } \\
\text { expensive [18]. }\end{array}$ \\
\hline Scheduled on-condition task & $\begin{array}{l}\text { The scheduled on-condition task is referred to as offline condition based maintenance (OFCBM) in this } \\
\text { paper and is an inspection performed on an equipment item at regular interval with the aim of detecting } \\
\text { potential failure [6]. The check carried out on equipment items is performed by maintenance } \\
\text { practitioners or operators with or without the use of diagnostic tools. This approach is effective and yet } \\
\text { more cost effective than the continuous on-condition task and as such more attractive to most industries } \\
\text { and the maritime industry inclusive. However the major challenge of the scheduled on-condition task is } \\
\text { the problem of determining the appropriate interval for performing inspection task [18]. }\end{array}$ \\
\hline
\end{tabular}

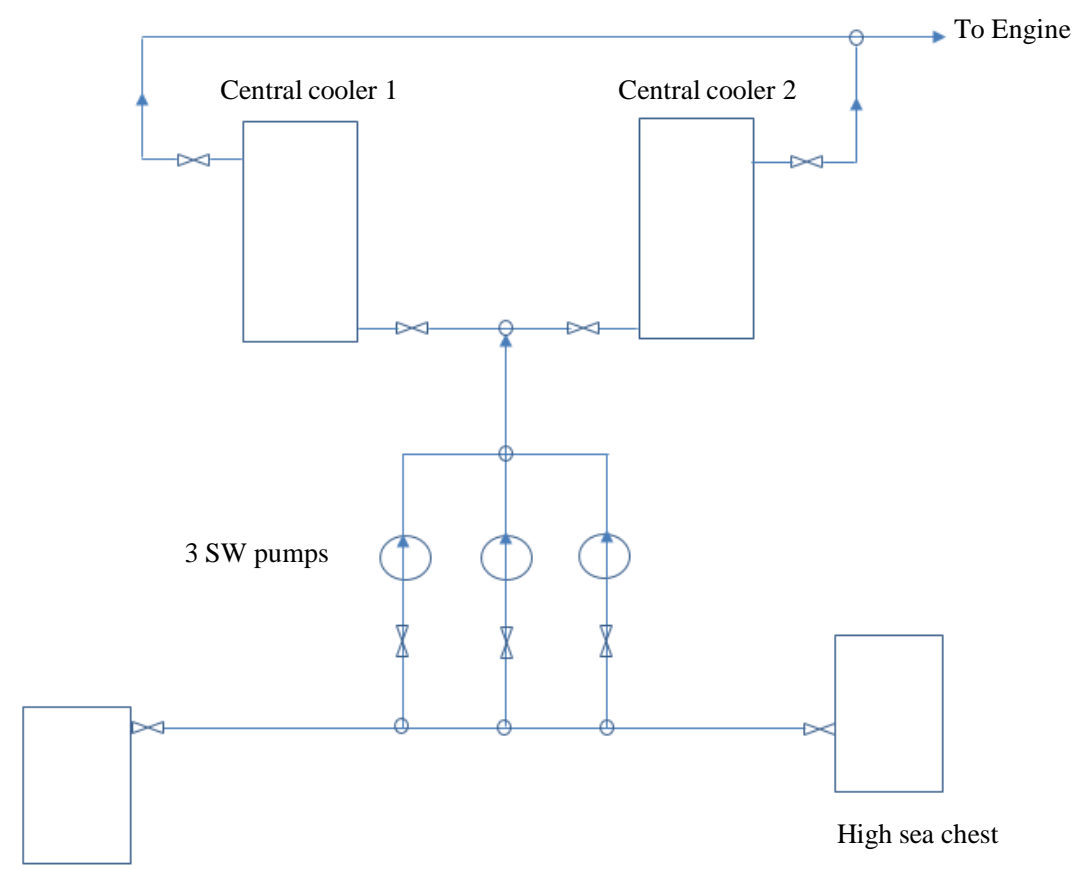

Low sea chest

Figure 1. Central cooling system of a bulk carrier, modified from [20].

Equipment damage cost (C4). The cost consequences as a result of plant system equipment damage for each maintenance strategy.

Personnel safety (C5). Some equipment/components failure can cause serious injury or death of personnel on board ship. Maintenance strategy is generally chosen based on its ability to eliminate or reduce such failure.

Equipment safety (C6). In the event of failure of a particular component/equipment item, the question is how safe is the entire system. Greater attention is paid to parts that may result in severe damage to the system. A maintenance strategy that will reduce failure frequency to the lowest level is advisable. 
Environment safety (C7). Failure of some parts of the marine machinery system can result in serious environmental hazards. The maintenance strategy is generally chosen based on its ability to eliminate or reduce such failures.

Minimisation of operational loss (C8). For each of the maintenance strategy there is an associated operational loss. Generally the preventative maintenance approach has greater capacity to minimise operational loss.

Equipment reliability (C9). Different maintenance strategy yield varying plant system reliability and the optimum solution is the one that will produce the highest reliability.

System failure characteristics (C10). The component failure characteristics; wear-in failure, random and wear-out failure are a key factor in selecting the most appropriate maintenance strategy for plant equipment. For example, Condition Based Maintenance (CBM) is suitable for components with random failure patterns, provided there is an identifiable warning sign for measuring the condition of the component.

Available monetary resource (C11). This is a vital factor in determining the optimum maintenance strategy. For example if available finance for maintaining the system cannot incorporate CBM, the plant manager is left with no choice other than to use alternative approach irrespective of the benefits of the CBM.

Equipment risk level (C12). Generally CBM strategy is preferred for very high risk equipment whose failure may result to irreversible damage to personnel, environment and plant system.

\subsection{TOPSIS Data Gathering and Analysis}

Having defined the decision criteria against which the maintenance strategies will be ranked, the next step is to apply the ranking tools, TOPSIS in evaluating the optimum maintenance strategy. A 5 point Likert scale was applied in this study in obtaining information from the three experts who are presented in Table 2. Since the case study uses three experts in determining the optimum solution, each of the expert's information is used as input data into the TOPSIS methodology in turns to obtain their individual optimum solution.

In the application of TOPSIS to the sea water cooling pump of a marine diesel engine, the expert one information in the decision matrix in Table 2 was normalised using Equation (2) and the result is presented in Table 3. This is followed by the formation of the weighted normalised matrix using Equation (3) also shown in Table 3. Equations (4) and (5) were then applied to evaluate the positive ideal and negative ideal solutions respectively and results are presented in Table 4. Finally, Equations (6)-(8) were used to obtain the distance of each maintenance strategy alternative to the positive-ideal solution $S_{i}^{+}$and to the negative-ideal solution $S_{i}^{-}$together with relative closeness $P_{i}$ of each maintenance strategy to the ideal solution and the results of $P_{i}$ together with their rankings are shown in Table 5.

From Table 5, the best alternative is the OFCBM since it has the highest performance index of 0.9972 which is closest to the ideal solution. The ONCBM occupies the second position with a performance index of 0.8131 and the least preferred alternative is CM having the lowest performance index of 0.1357 and being in the last position.

The same TOPSIS methodology were followed in analysing expert 2 and 3 information and the results obtained are presented in Table 6 and Table 7 respectively.

The overall scores of maintenance strategy alternatives were evaluated by averaging the individual expert's scores and the result is shown in Table 8. From the result, OFCBM occupies the first position having an overall score of 0.9542 . Hence the optimum maintenance strategy is OFCBM. The second most preferred alternative is the ONCBM and the least preferred choice is CM with the lowest overall score of 0.1639 . The CM approach being ranked in the last position is a clear indication that the marine industries is fast shifting from the reactive maintenance approach to Condition Based Maintenance methodology. Although OFCBM and ONCBM are both Condition Based Maintenance technique the preference for the OFCBM methodology may be as a result of the desire by most marine industries to minimise maintenance cost whilst maintaining optimum reliability of ship systems.

In validating the proposed methodology, the technique was compared with other approaches; AHP and PROMETHEE. From the comparative analysis, results show that the three techniques produce OFCBM as the best maintenance strategy for maintaining sea water cooling pump. Although AHP and PROMETTHE produces the same optimum solution with the TOPSIS methodology but the limitations of the AHP and PROMETHEE will make them unattractive to maintenance practitioners. The AHP as ranking tool will result to obtaining numerous pairwise comparison judgement which will make the evaluation process complicated. The PROMETHEE 
Table 2. Experts judgement of maintenance alternatives.

\begin{tabular}{|c|c|c|c|c|c|c|c|c|c|c|c|c|c|c|c|}
\hline \multirow{3}{*}{ Criteria } & \multicolumn{15}{|c|}{ Rating of maintenance alternatives } \\
\hline & \multicolumn{5}{|c|}{ Expert 1} & \multicolumn{5}{|c|}{ Expert 2} & \multicolumn{5}{|c|}{ Expert 3} \\
\hline & $\mathrm{CM}$ & $\mathrm{SOH}$ & SRP & OFCBM & ONCBM & $\mathrm{CM}$ & $\mathrm{SOH}$ & SRP & OFCBM & ONCBM & $\mathrm{CM}$ & $\mathrm{SOH}$ & SRP & OFCBM & ONCBM \\
\hline $\mathrm{C} 1$ & 1 & 3 & 3 & 5 & 5 & 2 & 3 & 2 & 4 & 4 & 1 & 2 & 1 & 5 & 4 \\
\hline $\mathrm{C} 2$ & 2 & 3 & 3 & 4 & 2 & 5 & 4 & 3 & 4 & 3 & 2 & 2 & 1 & 5 & 3 \\
\hline $\mathrm{C} 3$ & 5 & 4 & 3 & 4 & 2 & 4 & 3 & 4 & 5 & 3 & 5 & 3 & 1 & 2 & 1 \\
\hline C4 & 1 & 3 & 3 & 5 & 5 & 1 & 2 & 4 & 5 & 5 & 1 & 4 & 4 & 5 & 5 \\
\hline C5 & 1 & 3 & 4 & 5 & 5 & 1 & 3 & 2 & 5 & 5 & 1 & 4 & 3 & 5 & 5 \\
\hline C6 & 1 & 4 & 3 & 5 & 5 & 1 & 3 & 3 & 5 & 5 & 1 & 4 & 3 & 5 & 5 \\
\hline C7 & 1 & 2 & 3 & 5 & 3 & 2 & 3 & 3 & 5 & 5 & 5 & 2 & 2 & 4 & 2 \\
\hline C8 & 1 & 3 & 3 & 5 & 5 & 2 & 3 & 3 & 4 & 5 & 1 & 4 & 2 & 5 & 5 \\
\hline C9 & 1 & 2 & 3 & 5 & 5 & 2 & 4 & 3 & 5 & 4 & 1 & 4 & 2 & 5 & 5 \\
\hline C10 & 1 & 3 & 2 & 4 & 4 & 3 & 4 & 2 & 5 & 2 & 1 & 3 & 4 & 4 & 3 \\
\hline C11 & 4 & 3 & 3 & 5 & 2 & 5 & 3 & 1 & 4 & 1 & 3 & 3 & 1 & 5 & 3 \\
\hline C12 & 1 & 4 & 3 & 5 & 4 & 2 & 3 & 3 & 5 & 3 & 1 & 3 & 2 & 5 & 5 \\
\hline
\end{tabular}

Table 3. Normalised decision matrix and weighted normalised decision matrix.

\begin{tabular}{|c|c|c|c|c|c|c|c|c|c|c|}
\hline \multirow{2}{*}{ Criteria } & \multicolumn{5}{|c|}{ Normalised decision matrix } & \multicolumn{5}{|c|}{ Weighted normalised decision matrix } \\
\hline & $\mathrm{CM}$ & $\mathrm{SOH}$ & SRP & OFCBM & ONCBM & $\mathrm{CM}$ & $\mathrm{SOH}$ & SRP & OFCBM & ONCBM \\
\hline $\mathrm{C} 1$ & 0.1204 & 0.3612 & 0.3612 & 0.6019 & 0.6019 & 0.0010 & 0.0031 & 0.0031 & 0.0052 & 0.0052 \\
\hline $\mathrm{C} 2$ & 0.3086 & 0.4629 & 0.4629 & 0.6172 & 0.3086 & 0.0051 & 0.0077 & 0.0077 & 0.0102 & 0.0051 \\
\hline C3 & 0.5976 & 0.4781 & 0.3586 & 0.4781 & 0.2390 & 0.0027 & 0.0022 & 0.0016 & 0.0022 & 0.0011 \\
\hline $\mathrm{C} 4$ & 0.1204 & 0.3612 & 0.3612 & 0.6019 & 0.6019 & 0.0047 & 0.0142 & 0.0142 & 0.0237 & 0.0237 \\
\hline C5 & 0.1147 & 0.3441 & 0.4588 & 0.5735 & 0.5735 & 0.0372 & 0.1115 & 0.1487 & 0.1858 & 0.1858 \\
\hline C6 & 0.1147 & 0.4588 & 0.3441 & 0.5735 & 0.5735 & 0.0124 & 0.0496 & 0.0372 & 0.0619 & 0.0619 \\
\hline C7 & 0.1443 & 0.2887 & 0.4330 & 0.7217 & 0.4330 & 0.0156 & 0.0312 & 0.0468 & 0.0779 & 0.0468 \\
\hline C8 & 0.1204 & 0.3612 & 0.3612 & 0.6019 & 0.6019 & 0.0116 & 0.0349 & 0.0349 & 0.0581 & 0.0581 \\
\hline C9 & 0.1250 & 0.2500 & 0.3750 & 0.6250 & 0.6250 & 0.0121 & 0.0241 & 0.0362 & 0.0603 & 0.0603 \\
\hline C10 & 0.1474 & 0.4423 & 0.2949 & 0.5898 & 0.5898 & 0.0095 & 0.0284 & 0.0190 & 0.0379 & 0.0379 \\
\hline C11 & 0.5040 & 0.3780 & 0.3780 & 0.6299 & 0.2520 & 0.0324 & 0.0243 & 0.0243 & 0.0405 & 0.0162 \\
\hline C12 & 0.1222 & 0.4887 & 0.3665 & 0.6108 & 0.4887 & 0.0079 & 0.0314 & 0.0236 & 0.0393 & 0.0314 \\
\hline
\end{tabular}

Table 4. Positive and negative idea solution.

\begin{tabular}{cccc}
\hline Criteria & $Z^{+}$ & $Z^{-}$ \\
C1 & 0.0052 & 0.0010 \\
C2 & 0.0102 & 0.0051 \\
C3 & 0.0027 & 0.0011 \\
C4 & 0.0237 & 0.0047 \\
C5 & 0.1858 & 0.0372 \\
C6 & 0.0619 & 0.0124 \\
C7 & 0.0779 & 0.0116 \\
C8 & 0.0581 & 0.0121 \\
C9 & 0.0603 & 0.0095 \\
C10 & 0.0379 & 0.0162 \\
C11 & 0.0405 & 0.0079 \\
\hline
\end{tabular}


Table 5. Performance index $(P)$ and rank.

\begin{tabular}{ccccc}
\hline Alternatives & $S^{+}$ & $S^{-}$ & $P$ & Rank \\
\hline CM & 0.1876 & 0.0295 & 0.1357 & 5 \\
SOH & 0.1011 & 0.0929 & 0.4788 & 4 \\
SRP & 0.0711 & 0.1252 & 0.6376 & 3 \\
OFCBM & 0.0005 & 0.1892 & 0.9972 & 1 \\
ONCBM & 0.0407 & 0.1768 & 0.8131 & 2 \\
\hline
\end{tabular}

Table 6. Performance index $(P)$ and Rank for expert 2.

\begin{tabular}{ccccc}
\hline Alternatives & $S^{+}$ & $S$ & $P$ & Rank \\
\hline CM & 0.1736 & 0.0594 & 0.2549 & 5 \\
SOH & 0.0923 & 0.0917 & 0.4984 & 3 \\
SRP & 0.1312 & 0.0517 & 0.2826 & 4 \\
OFCBM & 0.0207 & 0.1751 & 0.8943 & 1 \\
ONCBM & 0.0466 & 0.1692 & 0.7840 & 2 \\
\hline
\end{tabular}

Table 7. Performance index $(P)$ and ranks for expert 3.

\begin{tabular}{ccccc}
\hline Alternatives & $S^{+}$ & $S^{-}$ & $P$ & Rank \\
CM & 0.2420 & 0.0272 & 0.1010 & 0.6718 \\
SOH & 0.0803 & 0.1643 & 0.4357 \\
SRP & 0.1421 & 0.1097 & 0.9712 \\
OFCBM & 0.0066 & 0.2233 & 0.2183 & 0.8891 \\
ONCBM & 0.0272 & & 2 \\
\hline
\end{tabular}

Table 8. Overall decision making score and ranks.

\begin{tabular}{cccccc}
\hline Maintenance alternatives & $\begin{array}{c}\text { Expert } 1 \text { TOPSIS } \\
\text { score }\end{array}$ & $\begin{array}{c}\text { Expert } 2 \text { TOPSIS } \\
\text { score }\end{array}$ & $\begin{array}{c}\text { Expert 3 TOPSIS } \\
\text { score }\end{array}$ & Overall score & Ranking \\
\hline CM & 0.1357 & 0.2549 & 0.1010 & 0.1639 & 5 \\
SOH & 0.4788 & 0.4984 & 0.6718 & 0.5497 & 3 \\
SRP & 0.6376 & 0.2826 & 0.4357 & 0.4520 & 4 \\
OFCBM & 0.9972 & 0.8943 & 0.9712 & 0.9542 & 1 \\
ONCBM & 0.8131 & 0.7840 & 0.8891 & 0.8287 & 2 \\
\hline
\end{tabular}

technique has limitations such as evaluation process complexity and the need for maintenance practitioners or analysts to determine preference function for each of the decision criteria. On the other hand the TOPSIS technique evaluation process is quiet simple irrespective of the number of decision criteria used in evaluating alternative maintenance strategies and these characteristics will make it attractive to the maintenance practitioners.

\section{Conclusion}

The proposed hybrid MCDM technique combines Delphi method, AHP and TOPSIS methods. While the Delphi method is used to screen decision criteria from literature such that the most important criteria are applied in selecting optimum maintenance strategy from among five alternatives identified for ship systems applications, the AHP and TOPSIS are utilised in the determination of weights of decision criteria and ranking of maintenance strategy alternatives respectively. The optimum solution obtained utilising the proposed method for the sea water pump is the Offline Condition Based Maintenance (OFCBM). This is in line with the current maintenance practice in many marine industries and this is evidence that the proposed methodology can suitably be applied 
for selection of maintenance strategy for the different equipment items of a ship system. The proposed technique has also been validated by comparing it with other hybrid MCDM approaches (AHP-AHP and AHP-PROMETHEE) and from the comparative analysis same optimum solution were produced. However the proposed approach evaluation process is less computationally intensive.

\section{References}

[1] BS (1993) Glossary of Terms Used in Terotechnology. Common BSI/ISO Standard, London.

[2] Arab, A., Ismail, N. and Lee, L.S. (2013) Maintenance Scheduling Incorporating Dynamics of Production System and Real-Time Information from Workstations. Journal of Intelligent Manufacturing, 24, 695-705. http://dx.doi.org/10.1007/s10845-011-0616-3

[3] Wang, C.-H. and Tsai, S.-W. (2014) Optimizing Bi-Objective Imperfect Preventive Maintenance Model for SeriesParallel System Using Established Hybrid Genetic Algorithm. Journal of Intelligent Manufacturing, 25, 603-616. http://dx.doi.org/10.1007/s10845-012-0708-8

[4] Waeyenbergh, G. and Pintelon, L. (2004) Maintenance Concept Development: A Case Study. International Journal of Production Economics, 89, 395-405. http://dx.doi.org/10.1016/j.ijpe.2003.09.008

[5] Chareonsuk, C., Nagarur, N. and Tabucanon, M.T. (1997) A Multicriteria Approach to the Selection of Preventive Maintenance Intervals. International Journal of Production Economics, 49, 55-64. http://dx.doi.org/10.1016/S0925-5273(96)00113-2

[6] Rausand, M. and Vatn, J. (1998) Reliability Centered Maintenance. In: Soares, C.G., Ed., Risk and Reliability in Marine Technology, Balkema, Holland.

[7] Conachey, R.M. (2005) Development of Machinery Survey Requirement Based on Reliability-Centered Maintenance. ABS Technical Papers.

[8] American Bureau of Shipping (2004) Guidance Note on Reliability-Centered Maintence. America Bureau of Shipping.

[9] Goossens, A.J.M. and Basten, R.J.I. (2015) Exploring Maintenance Policy Selectionusing the Analytic Hierarchy Process. An Application for Naval Ships. Reliability Engineering and System Safety, 142, 31-41. http://dx.doi.org/10.1016/j.ress.2015.04.014

[10] Resobowo, D.S., Buda, K.A. and Dinariyana, A.A.B. (2014) Using Sensitivity Analysis for Selecting of Ship Maintenance Variables for Improving Reliability of Military Ship. Academic Research International, 5, 127.

[11] Delbecq, A.L., Van de Ven, A.H. and Gustafson, D.H. (1975) Group Techniques for Program Planning: A Guide to Nominal Group and Delphi Processes. Scott, Foresman Glenview.

[12] Kim, M., Jang, Y.-C. and Lee, S. (2013) Application of Delphi-AHP Methods to Select the Priorities of WEEE for Recycling in a Waste Management Decision-Making Tool. Journal of Environmental Management, 128, 941-948. http://dx.doi.org/10.1016/j.jenvman.2013.06.049

[13] Hwang, C.L. and Yoon, K. (1981) Multiple Attribute Decision Making: Methods and Applications. Springer-Verlag, New York.

[14] Emovon, I., Norman, R.A. and Murphy, A.J. (2014) A New Tool for Prioritising the Risk of Failure Modes for Marine Machinery Systems. Proceedings of the 33rd International Conference on Ocean, Offshore and Arctic Engineering OMAE14, California, 8-13 June 2014, 1-10. http://dx.doi.org/10.1115/omae2014-23267

[15] Khorshidi, R. and Hassani, A. (2013) Comparative Analysis between TOPSIS and PSI Methods of Materials Selection to Achieve a Desirable Combination of Strength and Workability in Al/SiC Composite. Materials \& Design, 52, 9991010. http://dx.doi.org/10.1016/j.matdes.2013.06.011

[16] Raju, K.S., Duckstein, L. and Arondel, C. (2000) Multicriterion Analysis for Sustainable Water Resources Planning: A Case Study in Spain. Water Resources Management, 14, 435-456. http://dx.doi.org/10.1023/A:1011120513259

[17] Rausand, M. (1998) Reliability Centered Maintenance. Reliability Engineering \& System Safety, 60, 121-132. http://dx.doi.org/10.1016/S0951-8320(98)83005-6

[18] Jardine, A.K.S., Lin, D. and Banjevic, D. (2006) A Review on Machinery Diagnostics and Prognostics Implementing Condition-Based Maintenance. Mechanical Systems and Signal Processing, 20, 1483-1510. http://dx.doi.org/10.1016/j.ymssp.2005.09.012

[19] Emovon, I., Norman, R., Murphy, A.J. and Pazouki, K. (2015) An Integrated Multicriteria Decision Making Methodology Using Compromise Solution Methods for Prioritising Risk of Marine Machinery Systems. Ocean Engineering, 105, 92-103. http://dx.doi.org/10.1016/j.oceaneng.2015.06.005

[20] Desmi, A.P.V. and Grontmij Car Bro (2008) Optimisation of Pump and Cooling Water Systems. 